\title{
Gastro-oesophageal reflux related cough and its response to laparoscopic fundoplication
}

\author{
Christopher J Allen, Mehran Anvari
}

\begin{abstract}
Background-This study was designed to determine prospectively the rate of cough before and after laparoscopic Nissen fundoplication performed for the control of gastro-oesophageal reflux disease.

Methods-One hundred and ninety five consecutive patients ( 76 men) of mean (SD) age 46.9 (14.1) years with proven gastro-oesophageal reflux disease, who were either on long term omeprazole $(n=$ 187) or who had not responded to a trial of omeprazole $(n=8)$, took part in the study which was carried out in a university teaching hospital that included a regional respiratory referral centre. Patients underwent oesophageal manometry, 24 hour oesophageal pH testing, and symptom score evaluation by an independent observer before and six months after laparoscopic Nissen fundoplication.

Results-One hundred and thirty three patients presented with reflux symptoms and 62 with respiratory symptoms; $68 \%$ of patients complained of cough before surgery $(86 \%$ with respiratory symptoms, $60 \%$ with gastrointestinal symptoms). The percentage reflux time in 24 hours fell significantly $(p<0.0001)$ from a mean (SD) of $9.38(10.99) \%$ to $1.22 \quad(2.92) \%$, lower oesophageal sphincter tone rose significantly $(p<0.0001)$ from a mean (SD) of $7.71(5.90) \mathrm{mm} \mathrm{Hg}$ to $21.74(10.84) \mathrm{mm} \mathrm{Hg}$, and the cough score fell from a median value of 8.0 (IQR 12.0) to 0 (IQR 3) following surgery. Of the patients with cough, $51 \%$ were cough free after surgery and $31 \%$ improved. The patients with respiratory symptoms had a higher cough score before (median 12.0 (IQR 5.5) versus 4.0 (IQR 8.75), $p<0.0001$ ) and after surgery (median 1 (7.5) versus 0.0 (IQR 1.0), p = $0.0045)$ than those with gastrointestinal symptoms.

Conclusions-Patients who present to gastroenterologists with severe reflux commonly complain of cough. Laparoscopic Nissen fundoplication is effective in the control of cough in patients with gastro-oesophageal reflux disease, with or without primary respiratory disease. (Thorax 1998;53:963-968)
\end{abstract}

Keywords: cough; gastro-oesophageal reflux; laparoscopic fundoplication

Patients who present to respiratory physicians with chronic cough may have gastrooesophageal reflux as the primary cause $\mathrm{e}^{1-5}$ and the cough may improve with antireflux therapy. ${ }^{6}$ Larraine,${ }^{7}$ in a randomised controlled trial of medical and surgical treatment for reflux in patients with adult onset asthma, showed a statistically significant improvement with both cimetidine and antireflux surgery in a pulmonary symptom score which included cough. The rate of cough in reflux patients presenting to internists and gastroenterologists, the response of the cough to antireflux therapy, the relationship between cough and other symptoms of gastro-oesophageal reflux, and factors which may predict the response of reflux related cough to antireflux surgery remain unclear.

Despite the reported superiority of surgery over standard medical therapy in asthmatic patients, ${ }^{7}$ surgery has remained primarily as a last resort, reserved for the treatment of reflux in patients with repeated aspiration or clearly worsening respiratory conditions attributed to reflux. The morbidity, perioperative discomfort, and a six to eight week recovery period associated with standard open antireflux surgery have been the primary reasons why few patients or referring physicians have considered surgery as a viable treatment for patients with gastro-oesophageal reflux disease with respiratory complaints. Laparoscopic Nissen fundoplication, first described in $1991,{ }^{8}$ has been shown to be extremely effective in the treatment of gastro-oesophageal reflux disease symptoms and is associated with shorter hospital stay, recovery period, and early return to full activity compared with open fundoplication..$^{9-11}$ This has led to its use in some centres as an alternative option to long term omeprazole therapy. ${ }^{11}$

In this study we have evaluated the rate and severity of cough in 195 patients with documented gastro-oesophageal reflux disease on long term medical antireflux therapy who underwent laparoscopic Nissen fundoplication. Follow up evaluations were carried out to assess the response of cough and other symptoms of gastro-oesophageal reflux disease to this surgery, and the possible predictive factors which could allow early determination of patients' response to surgical treatment were analysed.

\section{Methods}

PATIENTS

Laparoscopic Nissen fundoplication was introduced into our institution in 1992. This report is based on the first 195 consecutive patients (76 men) to undergo this procedure between August 1992 and March 1995. The hospital is the regional referral centre for respiratory
5 June 1998

Accepted for publication

8 June 1998 
Table 1 Indications for surgery in 62 patients who presented primarily with respiratory symptoms

\begin{tabular}{lc}
\hline Reason for surgery & Number \\
\hline Persistent cough & 42 \\
Recurrent aspiration & 10 \\
Worsening asthma & 7 \\
Increasing pulmonary fibrosis & 2 \\
Persistent sore throat & 1 \\
Total & 62 \\
\hline
\end{tabular}

Table 2 Diagnoses of patients presenting primarily with respiratory symptoms

\begin{tabular}{lr}
\hline Diagnosis & No. \\
\hline Cough & 34 \\
Cough and pneumonia & 1 \\
Asthma & 14 \\
Asthma and aspiration & 1 \\
Aspiration & 6 \\
Alveolitis & 3 \\
COPD & 1 \\
Other & 2 \\
Total & 62 \\
\hline
\end{tabular}

medicine. The mean (SD) age of the patients was 46.9 (14.1) years (range 14-80). All had proven gastro-oesophageal reflux disease and were either on long term omeprazole $(n=187)$ or had been given a trial of omeprazole therapy without success $(n=8)$. All patients underwent gastroscopy, 192 underwent oesophageal manometry in our institution, 182 underwent 24 hour $\mathrm{pH}$ testing in our institution, and $178 \mathrm{had}$ symptom score evaluation by an independent observer as part of their preoperative assessment within one year of surgery. Some patients had additional investigations-namely, Bernstein test, cineradiology of the oesophagus, or a gastric emptying study when clinically indicated.

The indication for surgery was inadequate control of symptoms despite maximal medical treatment (including bed elevation, antireflux diet, prokinetic agent, and omeprazole in doses varying from 40 to $80 \mathrm{mg} /$ day) in 119 patients, while the remaining 76 patients were symptomatically well controlled on long term omeprazole but chose to have surgery in preference to long term omeprazole therapy (doses 20-80 $\mathrm{mg}$ /day). For 62 of the 119 patients with inadequate control of symptoms the primary indication for surgery was the control of respiratory symptoms (table 1). The most frequent respiratory indication for surgery was persistent cough.

ASSESSMENT OF PATIENTS PRESENTING PRIMARILY WITH RESPIRATORY COMPLAINTS

Our approach to the assessment of patients with persistent cough suspected of having reflux relies on a close collaboration between

Table 3 Correlation between cough and reflux symptoms before surgery

\begin{tabular}{|c|c|c|c|c|c|c|c|c|}
\hline & \multicolumn{2}{|c|}{ Heartburn } & \multicolumn{2}{|l|}{ Pain } & \multicolumn{2}{|c|}{ Regurgitation } & \multicolumn{2}{|c|}{ Dysphagia } \\
\hline & $r$ & pvalue & $r$ & $p$ value & $r$ & $p$ value & $r$ & $p$ value \\
\hline Pain & 0.328 & $<0.0001$ & & & & & & \\
\hline Regurgitation & 0.471 & $<0.0001$ & 0.347 & $<0.0001$ & & & & \\
\hline Dysphagia & 0.159 & 0.0501 & 0.238 & 0.0035 & 0.271 & 0.0008 & & \\
\hline Cough & -0.012 & 0.8819 & -0.028 & 0.7300 & 0.056 & 0.4902 & 0.233 & 0.0040 \\
\hline
\end{tabular}

$\mathrm{r}=$ Spearman rank correlation.

Statistically significant correlations are shown in bold type. an internist or gastroenterologist, pulmonologist and surgeon. The patients are fully evaluated for treatable respiratory disease. ${ }^{1-4} \mathrm{In}$ addition to full respiratory work-up, methacholine challenge testing is used to exclude airway hyperresponsiveness as a cause of the cough or to assess patients with atypical asthma symptoms, ${ }^{19}$ and all patients are carefully evaluated for rhinitis, sinusitis, and medications that may cause or exacerbate cough (in particular, beta blockers and ACE inhibitors). If respiratory causes of cough have been ruled out, most patients (even without typical symptoms of gastro-oesophageal reflux disease) undergo initial investigation for reflux with 24 hour $\mathrm{pH}$ testing, endoscopy, oesophageal manometry, and Bernstein test. If gastrooesophageal reflux disease is confirmed, the patients are given a trial of medical antireflux therapy with diet, bed elevation, omeprazole, and a prokinetic drug (usually cisapride). Reflux symptoms, if present, typically respond within two weeks ${ }^{20}$ but the respiratory symptoms may take at least three months to improve. ${ }^{1{ }^{20}}$ If the respiratory symptoms persist after at least three months of effective antireflux therapy the patients are offered a consultation with a surgeon to discuss laparoscopic Nissen fundoplication.

The 62 patients who presented primarily with respiratory complaints had a mean (SD) age of 47.3 (15.1) years, $65 \%$ were women, and $68 \%$ were lifetime non-smokers. Fifty five of these patients had been assessed by a pulmonologist, one by an allergist, one by an internist, one by a head and neck surgeon, one by a gastroenterologist, and three were referred by their family physician. The respiratory diagnoses in these patients are listed in table 2 .

The chest radiographs were normal at the time of surgery in $73 \%$ of the patients. The abnormalities were usually focal changes of scarring or atelectasis related to previous pneumonia; in three patients there were changes of diffuse interstitial lung disease. Fifty eight of the patients had specific respiratory investigations: 42 had allergy skin tests ( 22 positive to at least one common allergen) and 54 patients had either pulmonary function testing or a methacholine inhalation test or both tests depending on the clinical situation. All the asthmatic patients tested had a positive methacholine test; 23 patients with cough were tested of which 22 were normal and one had mildly increased airways responsiveness (with cough as the predominant symptom). Forty one patients had full pulmonary function testing with measurement of spirometric values, lung volumes, and carbon monoxide transfer factor. Pulmonary function was normal in 19 patients, 12 showed an isolated reduction in transfer factor, four a non-obstructive defect with reduced transfer factor, one an obstructive defect with reduced transfer factor, four patients had a non-obstructive defect with normal transfer factor, and one had an obstructive defect with normal transfer factor. 
Table 4 Results of investigations before and six months after surgery $(n=154)$

\begin{tabular}{llccc}
\hline & Before surgery & $\begin{array}{l}\text { Six months after } \\
\text { surgery }\end{array}$ & Difference (95\% CI) & p value \\
\hline Median (IQR) heartburn score & $12(8)$ & $0(1)$ & $7.45(6.00$ to 9.00$)$ & $<0.0001$ \\
Mean (SD) LES tone (mm Hg) & $7.71(5.90)$ & $21.74(10.84)$ & $14.06(12.09$ to 16.03$)$ & $<0.0001$ \\
Mean (SD) 24 hour pH <4 (\%) & $9.38(10.99)$ & $1.22(2.92)$ & $8.44(6.49$ to 10.45$)$ & $<0.0001$ \\
Median (IQR) cough score & $8(12)$ & $0(3)$ & $4(3.50$ to 5.50) & $<0.0001$ \\
\% patients with cough & 69 & 31 & & $<0.0001$ \\
\hline
\end{tabular}

LES = lower oesophageal sphincter.

OPERATIVE TECHNIQUE

The surgical technique has been previously described. ${ }^{11}$ In short, after insertion of five trocars into the abdomen the oesophagus was mobilised for a distance of $5 \mathrm{~cm}$. The fundus of the stomach was brought through a window behind the oesophagus and three interrupted sutures were used to fashion a standard Nissen fundoplication by approximating fundusoesophagus-fundus. The sutures were placed $1-1.5 \mathrm{~cm}$ apart ensuring a wrap of $2-3 \mathrm{~cm}$ in length. The wrap was constructed over a 42-52 French bougie placed intraluminally within the oesophagus. The choice of the bougie size was based on preoperative assessment of oesophageal motor function. ${ }^{12}$ Short gastric vessels were divided only if necessary to achieve desired looseness of the wrap. The cura were re-approximated if the oesophageal hiatus was considered large enough to allow herniation of intra-abdominal viscera.

\section{HEARTBURN AND COUGH SYMPTOM SCORE \\ ASSESSMENT}

Preoperatively and at six months following the surgery, patients were asked by trained independent observers about heartburn, retrosternal/epigastric pain, regurgitation, dysphagia, and cough. For each symptom the patients were asked the two questions: "How much does this problem bother you?" and "How often do you have this problem?" The severity was classified as not at all (0), mild (1), moderate (2), severe (3). The frequency was classified by the observer as 0 if the symptom was absent, once a month (1), once a week (2), 2-4 times a week (3), daily (4). The scores for severity and frequency were multiplied together resulting in possible scores from 0 to 12 for each symptom-the higher the score the worse the symptom. This scoring system has previously been shown to give valid results. ${ }^{11} 13$

POSTOPERATIVE FOLLOW UP

Each patient was invited to undergo repeat oesophageal manometry, 24 hour $\mathrm{pH}$ testing, and symptom score assessment at six months following their surgery.

Table 5 Median (IQR) improvement in cough symptom scores after surgery of patients with cough before surgery in respiratory and gastrointestinal groups

\begin{tabular}{lccc}
\hline & Respiratory group & $\begin{array}{l}\text { Gastrointestinal } \\
\text { group }\end{array}$ & p value $^{*}$ \\
\hline Number of patients & 44 & 62 & \\
Preoperative & $12.0(4.0)$ & $8.0(6.0)$ & 0.0032 \\
Postoperative & $2.5(8.0)$ & $0.0(3.0)$ & 0.0201 \\
$\begin{array}{l}\text { Change in cough score } \\
\quad \text { (preoperative-postoperative) }\end{array}$ & $8.0(8.5)$ & $7.0(6.0)$ & 0.9412 \\
p value & $<0.0001$ & $<0.0001$ & \\
\hline
\end{tabular}

${ }^{\star} \mathrm{p}$ values for respiratory group versus gastrointestinal group (Mann-Whitney $U$ test). $\mathrm{p}$ values for preoperative versus postoperative (Wilcoxon ranked sign test).
STATISTICAL ANALYSIS

All data were analysed using Statview 4.01 for the Macintosh. Paired and unpaired $t$ tests were used for comparison of parametric data. For non-parametric data the Mann-Whitney U test for unpaired data, Wilcoxon signed rank test and McNemar chi square for paired data, and the Spearman rank correlation test were used. Parametric data are expressed as mean (SD), non-parametric data as median (interquartile range, IQR). $\mathrm{p}$ values of $<0.05$ were considered statistically significant.

\section{Results}

PREOPERATIVE SYMPTOM SCORES

There were 17 patients from whom preoperative symptom scores could not be obtained. These patients were similar to the remaining 178 patients with regard to their 24 hour $\mathrm{pH}$ scores (unpaired $t=1.248, \mathrm{p}=0.2137$ ) and lower oesophageal sphincter tone (unpaired $t=$ $1.034, \mathrm{p}=0.3020)$. Of 178 patients who completed preoperative symptom scores, 149 (84\%) complained of heartburn, 157 (88\%) of regurgitation, $138(76 \%)$ of epigastric or retrosternal pain, 95 (53\%) of dysphagia, and 119 $(69 \%)$ of cough. Table 3 shows a correlation matrix for the reflux symptom scores and cough scores. There was a significant correlation between cough score and dysphagia score $(\mathrm{p}=0.0040)$, but no correlation between cough and heartburn, regurgitation, epigastric or retrosternal pain. There were significant correlations between heartburn, regurgitation, dysphagia, and epigastric or retrosternal pain (table 3). Of the 119 patients who complained of cough, 21 (18\%) denied heartburn, 15 (13\%) denied regurgitation, $10(8 \%)$ denied both heartburn and dysphagia, 25 (21\%) denied epigastric or retrosternal pain, 50 (42\%) denied dysphagia, and six patients $(5 \%)$ denied heartburn, regurgitation, and epigastric or retrosternal pain. Thus, six patients (5\%) complained of cough and no typical symptoms of reflux. Five of these were respiratory patients (in four the respiratory diagnosis was cough and in one aspiration), and the other patient presented with dysphagia without heartburn, regurgitation or pain.

OPERATIVE DATA

One hundred and ninety one out of 195 patients underwent successful laparoscopic fundoplication. Four patients in whom adequate visualisation of the oesophageal hiatus was not achieved were converted to open fundoplication. The mean (SD) operative time was 67.9 (30.8) minutes (range 30-195). There were no intraoperative complications and three clinically important postoperative 
Table 6 Response of cough to surgery: comparison of preoperative findings

\begin{tabular}{|c|c|c|c|c|c|}
\hline & $n$ & $\begin{array}{l}\text { Median }(I Q R) \\
\text { preoperative cough } \\
\text { score }\end{array}$ & $\begin{array}{l}\text { Median }(I Q R) \\
\text { preoperative } \\
\text { heartburn score }\end{array}$ & $\begin{array}{l}\text { Mean (SD) preoperative } \\
24 \text { hour } p H(\%)\end{array}$ & $\begin{array}{l}\text { Mean }(S D) \text { preoperative } \\
\text { lower oesophageal sphincter } \\
\text { tone }(\mathrm{mm} \mathrm{Hg})\end{array}$ \\
\hline \multirow{4}{*}{$\begin{array}{l}\text { Responders } \\
\text { Non-responders } \\
95 \% \text { CI on difference } \\
\text { p value }\end{array}$} & 90 & $12.0(4.0)$ & $12.0(8.0)$ & $8.74(11.21)$ & $8.52(6.19)$ \\
\hline & \multirow{3}{*}{19} & $8.0(8.0)$ & $8.0(10.75)$ & $12.56(13.48)$ & $5.26(4.28)$ \\
\hline & & & & -2.17 to 9.80 & -6.22 to -0.291 \\
\hline & & 0.1875 & 0.2704 & $\mathrm{t}=1.265, \mathrm{p}=0.2087$ & $\mathrm{t}=-2.177, \mathrm{p}=0.0317$ \\
\hline
\end{tabular}

complications requiring re-surgery. One was a delayed oesophageal leakage occurring two days postoperatively and the other two were transhiatal herniation of the stomach associated with postoperative cough: in one case, in which no crural repair had been carried out at original surgery, the herniation was reduced laparoscopically, and the other in which a crural repair had been done at the time of original surgery required a laparotomy to achieve reduction of the herniated stomach. Neither of the two patients who herniated were respiratory patients and neither complained of cough preoperatively.

SIX MONTH FOLLOW UP

Of the 178 patients with complete preoperative assessment, 22 patients refused follow up investigation or could not be traced and two did not return for scheduled follow up. These 24 patients without postoperative follow up had similar preoperative 24 hour $\mathrm{pH}$ scores (incomplete mean (SD) 7.43 (4.61) versus complete mean (SD) 9.37 (10.99), $t=0.837$, p $=0.4039)$, lower oesophageal sphincter tone (incomplete mean (SD) 6.96 (6.16) versus complete mean (SD) 7.71 (5.90), $t=0.755$, p $=0.5703$ ), cough scores (incomplete median 4 (IQR 10) versus complete median 8 (IQR 12), $\mathrm{p}=0.2224$ ), and heartburn scores (incomplete median 12 (IQR 5) versus complete 12 (IQR $8), p=0.4015$ ) compared with the patients who completed follow up. The preoperative and postoperative results for the 154 patients with complete follow up are summarised in table 4 and these are the data used in all the analyses that follow.

IMPROVEMENT IN COUGH SIX MONTHS AFTER SURGERY

Eighty three percent of patients experienced either cure or improvement in their cough six months after surgery and 93\% experienced either cure or improvement in their heartburn after surgery. The patients were separated into those patients who underwent surgery primarily for control of respiratory symptoms related to reflux (respiratory patients, $\mathrm{n}=51$ ) and those operated on primarily for reflux symptoms (gastrointestinal patients, $\mathrm{n}=103$ ). Preoperatively, these groups were indistinguishable with regard to their lower oesophageal sphincter tone (mean (SD) 7.51 (6.81) versus 7.81 (5.43), unpaired $t=0.299, \mathrm{p}=$ $0.7654)$ and 24 hour $\mathrm{pH}$ profile $(8.30(7.49)$ versus 9.92 (12.41), unpaired $t=0.827, \mathrm{p}=$ $0.4095)$, indicating that their reflux was of similar severity.

Eighty six percent of the respiratory patients complained of cough before surgery compared with $60 \%$ of the gastrointestinal patients and the respiratory patients had significantly higher cough scores (median 12 (IQR 5.5) versus 4 (8.75), p<0.0001, Mann-Whitney). The respiratory and gastrointestinal patients had similar heartburn (median 10.5 (IQR 11.0) versus 12.0 (6), $\mathrm{p}=0.1632$, Mann-Whitney), dysphagia $(4.0(12.0)$ versus $0(9.0), \mathrm{p}=0.2791$, Mann-Whitney), regurgitation (8.0 (10.0) versus 8.0 (12.0), $\mathrm{p}=0.1916$, Mann-Whitney), and epigastric/retrosternal pain scores (6 (12) versus 9 (9), $\mathrm{p}=0.0765$, Mann-Whitney).

Postoperatively the respiratory and gastrointestinal patient groups showed a similar fall in heartburn score (median 9 (IQR 12) versus 9 (8), $p=0.7778$, Mann-Whitney). The rate of heartburn was similar in the two groups but the rates of cough were significantly different (see above). To compare changes in cough in the two groups only patients with cough before surgery were compared (table 5). The respiratory patients had significantly higher cough scores both before and after surgery but the absolute changes in cough were similar in the two groups (table 5). Thus, surgery was equally effective in controlling cough in both patient groups.

PREOPERATIVE MEASUREMENTS THAT MAY PREDICT IMPROVEMENT IN COUGH AFTER SURGERY

Patients were classified into patients whose cough score fell after surgery (responders) and those whose cough score was either unchanged or increased (non-responders) and the data are presented in table 6 . There was a tendency for the responders to have higher preoperative cough scores but this was not statistically significant. There were no differences in the preoperative heartburn scores or 24 hour $\mathrm{pH}$ scores between the two groups, but the non-responders did have a statistically significantly lower preoperative lower oesophageal sphincter tone.

Among the respiratory patients, $80 \%$ of those with cough, $75 \%$ of the asthmatics, all of those with aspiration, and $50 \%$ of those with interstitial lung disease responded with a reduction in cough score. Smoking history, airway responsiveness to methacholine, pulmonary function tests, or atopic status did not predict the likelihood of response to surgery (data not presented).

\section{Discussion}

This study presents further evidence of the effectiveness of laparoscopic Nissen fundoplication in the treatment of patients with gastrooesophageal reflux who have not responded to maximal medical therapy with omeprazole, or who have opted for surgery as an alternative to long term omeprazole therapy. Ninety three 
percent of patients with heartburn preoperatively experienced complete relief or clinically important improvement from heartburn six months after surgery. This symptomatic improvement was associated with normalisation of the 24 hour $\mathrm{pH}$ profile and the lower oesophageal sphincter tone.

Cough was a common complaint in patients who had presented to gastroenterologists, surgeons and internists with typical reflux symptoms. Two thirds of these patients complained of cough on direct questioning as part of their preoperative symptom score evaluation and it is likely that the cough was due to reflux as most patients experienced a highly statistically significant and clinically important improvement in their cough six months after surgery. Caution should be used in the interpretation of these results because the current study is a prospective consecutive case series rather than a randomised controlled trial. However, all patients had chronic respiratory and reflux disease that had been fully treated with maximal medical therapy for al least three months and it is unlikely that many would have improved without surgery.

One third of the patients who underwent antireflux surgery presented primarily with respiratory complaints (table 1) and most $(85 \%)$ of these patients complained of chronic cough as the main symptom. The cough scores were higher in the respiratory patients, but their reflux symptom scores, 24 hour $\mathrm{pH}$ scores and lower oesophageal sphincter tone were similar to the gastrointestinal patients. After surgery the respiratory patients showed just as good a response as the gastrointestinal patients in their cough scores, gastrointestinal symptoms scores, 24 hour $\mathrm{pH}$ score, and lower oesophageal sphincter tone. Thus, antireflux surgery is equally effective in control of cough and gastro-oesophageal reflux in both gastrointestinal and respiratory patients, which suggests that reflux is a clinically important cause of cough in both patient groups.

This study does not shed any direct light on why cough was so common in gastrointestinal patients with reflux, nor was it designed to do so. The preoperative cough symptom scores did not correlate with the preoperative scores for the typical reflux symptoms of heartburn, regurgitation, and pain, and the absolute change in cough scores after surgery did not correlate with the change in heartburn scores. This lack of correlation between cough and gastro-oesophageal reflux symptoms may suggest that there are different aetiologies for heartburn and cough in these patientsheartburn and pain arise from the local oesophageal effects of the refluxate ${ }^{14}$ whereas cough may be due to oesophagobronchial reflexes ${ }^{15}$ or oropharyngeal irritation and aspiration. Aspiration is more likely if there is disordered swallowing ${ }^{16}{ }^{17}$ and, consistent with this, was the correlation between dysphagia scores and cough scores (table 3 ).

An important question is how to determine which patients have reflux related cough. The presence and severity of heartburn and regurgitation do not predict the likelihood of reflux related cough. There was no correlation between severity of cough and severity of the reflux symptoms, and $16 \%$ of the patients with cough had no heartburn. Except for a slightly lower oesophageal sphincter tone in the non-responders, we are unable to demonstrate a preoperative profile that would predict a response of cough to antireflux surgery, although the improvement in cough scores after surgery parallelled the improvement in other indices of gastro-oesophageal reflux disease. Our experience emphasises, as has been shown by others, ${ }^{2}$ that there may be multiple causes of chronic cough. Other reports suggest that oesophageal $\mathrm{pH}$ monitoring with attention to the temporal relationship between episodes of acid reflux and cough may be the best way to select those patients who are most likely to experience improvement in their respiratory symptoms after anti-reflux therapy. ${ }^{18}$ If antireflux surgery was being considered for respiratory symptoms, we paid particular attention to the relationship between acid reflux and respiratory symptoms during 24 hour $\mathrm{pH}$ testing and acid infusion (Bernstein test) before surgery was recommended. Evaluation of our data indicates that most patients who continued to cough after surgery had an effective antireflux procedure when they had follow up motility and $\mathrm{pH}$ testing so that in our patients we believe that those who continued to cough after surgery did not have reflux related cough.

As the present study shows, patients who are evaluated and screened in this way have an excellent result in control of cough after surgery. In patients whose respiratory symptoms respond to initial medical therapy, a maintenance regimen with either $\mathrm{H}_{2}$ blockers or omeprazole may be necessary. Patients without significantly increased surgical risk who require long term maintenance therapy with omeprazole are given the option of laparoscopic Nissen fundoplication.

In conclusion, we have shown that laparoscopic Nissen fundoplication is an effective and safe surgical treatment for gastro-oesophageal reflux in patients who have either failed on maximal medical antireflux therapy (including omeprazole), or who are unable to manage without it, and who choose surgery in preference to long term omeprazole. Cough is another common symptom of gastrooesophageal reflux disease in patients who present for surgery and is equally well treated with laparoscopic Nissen fundoplication. As with all operations for reflux, long term follow up will be essential to confirm that these patients continue to benefit from their surgery.

We thank Dr Les Berman and Dr Serge Puksa for assistance with clinical information and follow up of patients they referred, and Dr C Goldsmith for his critical review of this paper.

1 Irwin RS, French CL, Curley FJ, et al. Chronic cough due to gastroesophageal reflux. Clinical, diagnostic, and pathogenetic aspects. Chest 1993;104:1511-7.

2 Irwin RS, Curley FJ, French CL. Chronic cough. The spectrum and frequency of causes, key components of the diagnostic evaluation, and outcome of specific therapy. Am Rev Respir Dis 1990;141:640-7.

3 Allen CJ, Newhouse MT. Gastroesophageal reflux and chronic respiratory disease. Am Rev Respir Dis 1984;129: 645-7. 
4 Fitzgerald JM, Allen CJ, Craven MA, et al. Chronic cough and gastroesophageal reflux. Can Med Assoc $\mathcal{F}$ 1989;140: $520-4$

5 Ing AJ, Ngu MC, Breslin AB. Chronic persistent cough and gastro-oesophageal reflux. Thorax 1991;46:479-83.

6 Ing AJ, Ngu MC, Breslin ABX. A randomised double-blind cross-over study of ranitidine in patients with chronic persistent cough associated with gastroesophageal reflux. $A m$ Rev Respir Dis 1992;145(Suppl):A11.

7 Larrain A, Carrasco E, Galleguillos F, et al. Medical and surgical treatment of nonallergic asthma associated with gastroesophageal reflux. Chest 1991;99:1330-5.

8 Dallemagne B, Weerts JM, Jehaes C, et al. Laparoscopic Nissen fundoplication: preliminary report. Surg Laparosc Endosc 1991;1:138-43.

9 Weerts JM, Dallemagne B, Hamoir E, et al. Laparoscopic Nissen fundoplication: detailed analysis of 132 patients. Surg Laparosc Endosc 1993;3:359-64.

10 Hinder RA, Filipi CJ, Wetscher G, et al. Laparoscopic Nissen fundoplication is an effective treatment for gastrosen fundoplication is an effective treatment for gastro

11 Anvari M, Allen CJ, Borm A. Laparoscopic Nissen fundoplication is a satisfactory alternative to long-term omeprazole. Br F Surg 1995;82:938-42.

12 Anvari M, Allen CJ. Prospective evaluation of dysphagia before and after laparoscopic Nissen fundoplication without routine division of short gastrics. Surg Laparosc Endosc 199;6:424-9.

13 Maddern GJ, Chatterton BE, Collins PJ, et al. Solid and liquid gastric emptying in patients with gastro-oesophageal reflux. Br F Surg 1985;72:344-7.

14 Bernstein LM, Baker LA. A clinical test for esophagitis. Gastroenterology 1958;34:760-81.

15 Ing AJ, Ngu MC, Breslin AB. Pathogenesis of chronic persistent cough associated with gastroesophageal reflux. Am f Respir Crit Care Med 1994;149:160-7.

16 Tibbling L. Wrong-way swallowing as a possible cause of bronchitis in patients with gastroesophageal reflux disease. Acta Otolaryngol 1993;113:405-8.

17 Gardner AM. Aspiration of food and vomit. $Q \mathcal{F}$ Med 1958; 27:227

18 DeMeester TR, Bonavina L, Iascone C, et al. Chronic respiratory symptoms and occult gastroesophageal reflux. A prospective clinical study and results of surgical therapy. Ann Surg 1990;211:337-45.

19 Corrao WM, Braman SS, Irwin RS. Chronic cough as the sole manifestation of asthma. N Engl f Med 1979;300:6337.

20 Harper PC, Bergner A, Kaye MD. Antireflux treatment for asthma. Improvement in patients with associated gastroesophageal reflux. Arch Intern Med 1987;147:56-60. 